Research Article

\title{
Review of the world patent information for April '2016 on the topic "biotechnology of cheeses: cheese, cheese preparations and making thereof"
}

\section{Information on the topic selected from all over the world}

\section{Cheese made of recombined milk and such product manufacture method \\ RU 2579680 (Russia)}

International patent classification A23C 19/005

Application: 2014114383/10, 11.04.2014

Date of publication: 10.04.2016

Convention priority: 07.02.2014 LT 2014018

Inventors: Fjadaravichjus Vitautas (Lithuania)

Proprietor: TOO «Mars-2» (Kazakhstan)

\section{Abstract}

a) Field: Food industry

b) Substance: inventions group relates to dairy industry. For manufacture of $24 \%$ fat cheese the method is performed in the following way.

One blends the mixture of water filtrate and defatted milk. One adds dehydrated milk fats, dry defatted milk residue, sodium caseinate and salt. One introduces a stabilizer into the high-speed mixer for joining dehydrated milk fats and dry milk substances. One performs the mixture stirring, $\mathrm{pH}$ regulation with citric acid, heating, homogenization, packaging by a hot method, cooling and maintenance. Preliminarily defatted milk is supplied by means of a pump into the heat exchanger where milk is heated to $45-48^{\circ} \mathrm{C}$ and delivered into the bactofuge. By means of the pump milk is supplied into the microfiltration unit where 6.9-8.9" ceramic filters are applied, their throughput capacity equal to $1.1-1.6 \mathrm{mcm}$ at a temperature of $48-53^{\circ} \mathrm{C}$. The filtrate is delivered into the pasteurizer where it is maintained at a temperature of $56.5-58.5^{\circ} \mathrm{C}$ until an alkaline phosphatase test yields a negative result. Then the produced mixture is cooled to a temperature equal to $4-6^{\circ} \mathrm{C}$ in the heat exchanger and is stored in intermediate vessels.

c) Effect: inventions group ensures preservation of the product natural composition and taste properties.

\section{Method for production of protein fermented milk product}

\section{RU 2582264 (Russia)}

International patent classification A23C 19/076, A23C 23/00

Application: 2015112766, 07.04.2015

Date of publication: 10.04 .2016

\author{
Volume 4 Issue 4 - 2016
}

\section{Olga N Musina}

Siberian Research Institute of Cheese-Making, Russia

Correspondence: Olga N. Musina, Head of the Scientific Information' Analyses Department, Siberian Research Institute of Cheese-Making (Department of Russian Academy of Sciences), Russia, Tel +738525646I2, Email musinaolga@gmail.com

Received: May 23, 2016 | Published: June 02, 2016

Inventors: Bessonova Olga Vitalevna (Russia), CHernopolskaja Natalja Leonidovna (Russia)

Proprietor: Omskij gosudarstvennyj agrarnyj universitet imeni P.A. Stolypina (Russia)

\section{Abstract}

a) Field: Food industry

b) Substance: Invention relates to dairy industry. Method for production of protein cultured milk product involves preparation of milk mixture consisting of milk and buttermilk at ratio of 1:1$1: 3$, which is pasteurised, cooled to fermentation temperature and combined starter of bifidobacteria and latococci in amount of 3-5 $\%$ to volume of mixture is introduced. Then mixture is ripening, clot is dehydrated and cooled. After that, additionally added 10 $\%$ fat cream, fermented starter F DVS ABY-3-Probio-Tec ${ }^{\mathrm{TM}}$ in immobilized form in amount of $25 \%$ of ready product weight, amino acid L-histidine, food additive "Keltrol®". Mixture is stirred and additionally cooled.

c) Effect: protein culture milk product has high nutritive and biological value, high probiotic and functional properties, as well as high organoleptic indices.

Method for the manufacture of a cream cheese

\section{AU 2015218558 (Australia)}

International patent classification A23C 19/076

Application: 20150218558, 28.08.2015 
Date of publication: 14.04 .2016

Priority: 20140017254, 30.09.2014

Inventors: Spiegel Thomas; Perez Rodriguez Diana; Ferraz Marco; Wolfschoon-Pombo Alan; Muxfeldt Dirk

Proprietor: KRAFT FOODS R.\&D., INC. (USA)

a) The claims defining the invention are as follows:

i. A method for the manufacture of a cream cheese, the method comprising:providing a milk- and cream-containing dairy composition;

ii. Fermenting the milk- and cream-containing dairy composition to form a mixture of curds and whey;forming a concentrated mixture by removing at least an aqueous portion from the mixture of curds and whey;

iii. Forming a cream cheese from the concentrated mixture;

iv. the method further comprising obtaining a retentate by ultrafiltrating and/or microfiltrating a mixture of skimmed milk and an acidic aqueous by-product of a cheese-making process, and:

A. Supplementing the milk- and cream-containing dairy composition with at least a portion of the retentate; and/or

B. Supplementing the concentrated mixture with at least a portion of the retentate.

\section{Filled cheese product}

\section{AU 2015230775 (Australia)}

International patent classification A23C 19/09

Application: 20150230775, 24.09.2015

Date of publication: 28.04 .2016

Priority: 20140018075, 13.10.2014

Inventors: Kempter Klaus; Marder Uwe

Proprietor: KRAFT FOODS R.\&D., INC. (USA)

\section{a) The claims defining the invention are as follows:}

i. An individually packaged cream-cheese laminate comprising first and second outer cream-cheese layers and a filling layer interposed there between.

ii. 2. The cream-cheese laminate according to claim 1, wherein the filling layer comprises a second cream-cheese, processed cheese, pesto, tomato sauce, salad cream, mayonnaise, mustard, marmalade, jam, jelly, chocolate, Marmite @, or a mixture of two or more thereof.

iii. The cream-cheese laminate according to claim 1 or claim 2 , wherein the cream-cheese comprises one or more stabilisers selected from the group consisting of gelatine, xanthan gum, carrageenan, locust bean gum, citrate and mixtures of two or more thereof.

iv. The cream-cheese laminate according to claim 3, wherein the stabilisers are present in an amount of from 1 to $5 \mathrm{wt} \%$, preferably from 2 to $4 \mathrm{wt} \%$. v. The cream-cheese laminate according to any of the preceding claims, wherein the cream-cheese has a solids content of 35 to 60 $\mathrm{wt} \%$, preferably from to $55 \mathrm{wt} \%$, more preferably from 44 to 50 $w t \%$, and/or wherein the cream-cheese has a protein content of from 6 to $20 \mathrm{wt} \%$, preferably from 10 to $18 \mathrm{wt} \%$, more preferably from 10 to $15 \mathrm{wt} \%$, based on the weight of the cream-cheese.

vi. The cream-cheese laminate according to any of the preceding claims, wherein a middle of the laminate has a thickness of $6 \mathrm{~mm}$ or less, preferably $5 \mathrm{~mm}$ or less, still more preferably $4 \mathrm{~mm}$ or less, and preferably at least $2 \mathrm{~mm}$.

vii. The cream-cheese laminate according to any of the preceding claims, wherein the filling layer is of a constant thickness, preferably wherein said thickness is $4 \mathrm{~mm}$ or less, more preferably $3 \mathrm{~mm}$ or less, still more preferably $2 \mathrm{~mm}$ or less, and preferably at least $1 \mathrm{~mm}$.

viii. The cream-cheese laminate according to any of the preceding claims, having a mass of $45 \mathrm{~g}$ or less, preferably $40 \mathrm{~g}$ or less, and preferably at least $25 \mathrm{~g}$.

ix. The cream-cheese laminate according to any of the preceding claims, wherein the filling layer is fully enclosed by the first and second outer cream cheese layers.

$\mathrm{x}$. The cream-cheese laminate according to any of the preceding claims, wherein the first and second cream-cheese layers are merged to form a single layer around the periphery of the laminate, wherein the thickness of said single layer is less than the thickness of a middle of the laminate.

xi. The cream-cheese laminate according to any of the preceding claims, wherein the cream-cheese laminate consists of the first and second outer cream cheese layer and the filling layer.

xii. A package comprising a plurality of the individually packaged cream-cheese laminates of any of the preceding claims.

xiii. A method for the manufacture of the cream-cheese laminate of any of the preceding claims, the method comprising providing a cream-cheese, and co-extruding the cream-cheese with a filling to produce a cream-cheese laminate.

xiv. The method according to claim 13, wherein the step of coextruding is conducted at a temperature of $70 \mathrm{oC}$ or above.

xv. The method according to claim 13 or claim 14, wherein the step of coextruding is conducted directly onto the packaging material to package the cream-cheese laminate.

xvi. The method according to any of claims 13 to 15 , wherein the cream cheese has been supplemented with milk protein concentrate and one or more.

xvii. The method according to any of claims 13 to 16 , wherein the cream-cheese is supplemented with milk protein concentrate in an amount of from 2 to $10 \mathrm{wt} \%$, preferably from 3 to $8 \mathrm{wt} \%$, more preferably from 4 to $6 \mathrm{wt} \%$, based on the weight of the creamcheese.

\section{Process for producing cream cheese \\ DK 2649884 (Denmark)}

International patent classification A23C 19/045, A23C 19/05, 
A23C 19/076, A23C 19/09, A23C 9/142, A23J 1/20, A23J 3/10

Application: 20130162334T, 04.04.2013

Date of publication: 25.04 .2016

Priority: 20120163565, 10.04.2012; 201261714 026P, 15.10.2012

Inventors: Wolfschoon-Pombo, Dr. Alan Frederick; Demmer, Dr. Thomas; Milosavljevic, Katerina; Spiegel, Thomas L; Hammer, Christian

Proprietor: Kraft Foods R.\&D., INC. (USA)

a) The claims defining the invention are as follows

i. A process for producing cream cheese, said process comprising the steps of preparing a milk blend, subjecting the milk blend to fermentation, and preparing cream cheese from the fermented milk blend, wherein a casein-enriched milk fraction is used in the preparation of the milk blend.

ii. The process according to claim 1, wherein the milk blend comprises optionally pasteurized milk, cream and the caseinenriched milk fraction.

iii. The process according to claim 1 or 2 , wherein the milk blend is fermented with lactic acid bacteria.

iv. The process according to any one of claims 1 to 3 , comprising a step of separating the fermented milk blend into a curd fraction and a liquid fraction, preferably by means of ultrafiltration or centrifugation

v. The process according to any one of claims 1 to 3 , wherein the fermented milk blend is not separated by a separation step and is further processed as a curd fraction.

vi. The process according to claims 4 or 5 , comprising a step of adding one or more cream cheese ingredients to the curd fraction.

vii. The process according to any one of claims 4 to 6 , comprising a step of homogenizing the curd fraction.

viii. The process according to claim 7 , comprising a texturizing step following the homogenizing step.

ix. The process according to any of claims 4 and 6 to 8 , wherein the liquid fraction is a whey fraction and the process comprises the steps of separating the whey fraction into a whey protein concentrate fraction and a lactose/minerals fraction, preferably by means of ultrafiltration, and adding the whey protein concentrate fraction, preferably in the form of functionalized whey proteins, to the curd fraction.

$\mathrm{x}$. The process according to any one of claims 1 to 9 , comprising a step of separating skim milk to produce the casein-enriched milk fraction and a whey protein fraction, preferably by means of microfiltration.

xi. The process according to claim 10, comprising the steps of separating the whey protein fraction into a whey protein concentrate fraction and a lactose/minerals fraction, preferably by means of ultrafiltration, and adding the whey protein concentrate fraction, preferably in the form of functionalized whey proteins, to the curd fraction.

xii. The process according to any one of claims 9 to 11 , comprising the steps of separating the lactose/minerals fraction into a lactose fraction and a minerals fraction, preferably by means of a sequence of nanofiltration and reverse osmosis or nanofiltration and evaporation, and adding to the curd one or both of the lactose fraction and the minerals fraction, either fully or in part.

xiii. The process according to any one of claims 9 to 12 , comprising the steps of concentrating the lactose/minerals fraction into a concentrated lactose/minerals fraction, preferably by means of reverse osmosis or evaporation, and adding to the curd the concentrated lactose/minerals fraction, either fully or in part.

xiv. The process according to any one of claims 1 to 13 , comprising the step of adding one or both of cream and sour cream as cream cheese ingredient to the curd.

xv. Cream cheese, preferably obtainable by the process according to any one of claims 1 to 14 , characterized by having

I. $(\mathrm{Ca}+\mathrm{P}) /$ casein weight ratio of $\geq 0.05$

II. whey protein/true protein weight ratio of $\geq 25.0 \%$

III. K content of $\geq 140 \mathrm{mg} / 100 \mathrm{~g}$ and

IV. actose content of $\geq 3.5 \mathrm{~g} / 100 \mathrm{~g}$.

xvi. A process for preparing a food product comprising cream cheese and one or more additional food product components, said process comprising the steps of producing cream cheese in accordance with any one of claims 1 to 14 and combining the cream cheese thus produced with the one or more additional food product components.

Novel strain of lactobacillus rhamnosus and its metabolites for use in inhibiting xanthine oxidase and treating gout

\section{CN 105497078 (China)}

International patent classification A23C 19/09, A23C 9/13, A23G 9/36, A23L 2/52, A23L 33/135, A61K 35/747, A61P 19/06, C12N $1 / 20$, C12R $1 / 225$

Application: 20151519096, 22.08.2015

Date of publication: 20.04 .2016

Priority: 201462040616P, 22.08.2014

Proprietor: Food Industry Research and Development Institute (TW)

a) The claims defining the invention are as follows

i. A method for reducing uric acid levels in a subject, the method comprising culturing Lactobacillus rhamnosus in a medium to form a composition and administering the composition to a subject in need thereof in an amount effective for reducing uric acid levels.

ii. The method of claim 1, wherein the Lactobacillus rhamnosus is Lactobacillus rhamnosus I21 deposited under Accession No. DSM 28876

iii. The method of claim 1, wherein the subject suffers from gout or hyperuricemia.

iv. The method of claim 1, further comprising removing the Lactobacillus rhamnosus from the composition prior to the administering step. 
v. The method of claim 1 , wherein the composition is administered orally, intramuscularly, intradermally, intravenously, subcutaneously, intraperitoneally, intranasally, mucosally.

vi. The method of claim 1, wherein the medium is de Man-RogosaSharpe (MRS) broth, milk, or a juice.

vii. The method of claim 1 , further comprising lyophilizing the composition to form a powder 8 . A composition for reducing uric acid levels in a subject, the composition comprising a metabolite of Lactobacillus rhamnosus, wherein the metabolite is an inhibitor of xanthine oxidase activity.

viii. The composition of claim 8 , wherein the Lactobacillus rhamnosus is Lactobacillus rhamnosus strain I21 deposited under Accession No. DSM 28876.

ix. The composition of claim 8 , wherein the composition is free of Lactobacillus rhamnosus.

x. The composition of claim 8, further comprising a pharmaceutically acceptable excipient selected from the group consisting of a buffer, a diluent, a disintegrant, a binding agent, an adhesive, a wetting agent, a polymer, a lubricant, a glidant, and a flavoring.

xi. The composition of claim 8, further comprising a food ingredient selected from the group consisting of an acidity regulator, an anticaking agent, an antioxidant, a bulking agent, a carrier, an emulsifier, a flavor enhancer, a glazing agent, a preservative, a stabilizer, a sweetener, a thickener, a nutrient additive, and a flavoring.

xii. A method for producing a composition for reducing uric acid levels in a subject, the method comprising inoculating a medium with Lactobacillus rhamnosus and culturing the Lactobacillus rhamnosus in the medium to form a composition.

xiii. The method of claim 13, wherein the Lactobacillus rhamnosus is Lactobacillus rhamnosus I21 deposited under Accession No. DSM 28876

xiv. The method of claim 13, further comprising removing the Lactobacillus rhamnosus from the composition.

$\mathrm{xv}$. The method of claim 13, wherein the medium is MRS broth, milk, or a juice.

xvi. The method of claim 13, further comprising lyophilizing the composition.

xvii. The method of claim 13, further comprising sterilizing the composition by pasteurization, irradiation, autoclave, or filtration.

xviii. The method of claim 17, wherein the culturing is carried out for 2 days at $37^{\circ} \mathrm{C}$

xix. The method of claim 19 , wherein a culture density prior to the removing step is $1 \times 10<9>$ cells $/ \mathrm{ml}$

Process for making colorless cheese dairy milk and colorless cheese obtained thereof

\section{CN I055I967I (China)} $475 / 14$

International patent classification A23C 19/00, A23C 9/15, C07D

Application: 20151546996, 31.08.2015
Date of publication: 27.04 .2016

Priority: 20140182 971, 30.08.2014

Proprietor: DMK Deutsches Milchkontor G.M.B.H. (DE)

\section{Abstract}

A method is proposed for the production of colorless vat milk, which comprises subjecting (a) vat milk to ultrafiltration, while a first permeate $\mathrm{P} 1$ and a first retentate $\mathrm{R} 1$ produces (b) the permeate $\mathrm{P} 1$ to a reverse osmosis is subjected, while a second permeate $\mathrm{P} 2$ and a second $\mathrm{R} 2$ retentate prepared, (c) treating the second retentate $\mathrm{R} 2$ with an adsorbent and thereby a further retentate R2* is prepared, (d) the thus obtained retentate $\mathrm{R} 2$ pooled with the retentate and the permeate R1 P2.

\section{Method for producing a cheese and cheese produced - US 2016100600 (USA)}

International patent classification A23C 19/028, A23C 19/05, A23C $19 / 068$

Application: 201414892612, 21.05.2014

Date of publication: 14.04 .2016

Priority: 20130054 517, 21.05.2013; 2014 FR 51 186, 21.05.2014, PCT

\section{(FR) Proprietor: INGREDIA}

\section{- The claims defining the invention are as follows}

A. A method for producing a cheese having spreading and/or ropy properties when cooked, comprising:

B. Introducing a base composition comprising water, fat and milk protein concentrates into a solid-liquid mixer;

C. Operating the solid-liquid mixer at a stirring speed greater than or equal to $1500 \mathrm{rpm}$ and a first temperature between $35^{\circ} \mathrm{C}$. aid $60^{\circ} \mathrm{C}$., so as to emulsify and homogenize said base composition, then deaerating the base composition under vacuum, until a homogeneous, emulsified and deaerated dough, or pre-cheese mix, is obtained;

D. Cooling the dough or ore-cheese mix at a second temperature below the first temperature,

E. Adding one or more coagulating enzymes to the cooled dough or ore-cheese mix to cause coagulation in the cooled dough or precheese mix

F. Texturing the dough or ore-cheese mix, the texturing comprising the addition to said dough or ore-cheese mix of steam or hot water at a third temperature greater than or equal to $45^{\circ} \mathrm{C}$,

G. A moulding/and/or unmoulding the dough or ore-cheese mix, wherein said method does not comprise separating whey formed after addition of the one or more coagulating enzymes, and wherein a ratio between the weight of calcium and a total nitrogenous matter (TNM) in said milk protein concentrates is greater than or equal to $0.10 \%$ and less than or equal to $2.80 \%$.

H. The method according to claim 1, comprising after step ii), but before the texturing, and/or after the cooling, adding fat, to the dough or pre-cheese mix, while the dough or pre-cheese mix is subjected to a vacuum. 
I. The method according to claim 2 , wherein the quantity by weight of fat added to the dough or pre-cheese mix is greater than or equal to the quantity by weight of the total fat added to the base composition during step i).

J. The method according to claim 1, wherein the texturing comprises:spinning and stretching the dough or pre-cheese mix.

$\mathrm{K}$. The method according to claim 1 , wherein a ratio between the weight of the calcium and the weight of the total nitrogenous matter (TNM) in the milk protein concentrates is between $1.20 \%$ and $2.80 \%$.

L. The method according to claim 1, wherein the adding comprises the acidification of said cooled dough or pre-cheese mix at a $\mathrm{pH}$ greater than or equal to 5.10 and less than or equal to 5.40 .

M. The method according to claim 1, wherein the milk protein concentrates comprise less than $10 \%$ by weight of lactose in relation to the total weight of the milk protein concentrates.

N. The method according to claim 1 , wherein the dough or pre-cheese mix has a dry matter content of $40 \%$ to $65 \%$ by weight.

O. The method according to claim 1, wherein the milk protein concentrates have a casein/TNM weight ratio greater than 0.50 .

P. The method according to claim 1, comprising a second cooling of the dough or pre-cheese mix at the conclusion of the texturing, the second cooling being performed using cold water and/or ice water.

Q. The method according to claim 1, comprising a heat treatment step at the conclusion of step ii), and before step iii), during which the dough or pre-cheese mix is subjected to a temperature greater than or equal to $65^{\circ} \mathrm{C}$.

R. A mozzarella cheese, produced according to the method of claim 1, wherein the mozzarella cheese has ropy and/or spreading properties when cooked, wherein the mozzarella cheese has a weight ratio of TNM to the mozzarella cheese of less than or equal to $21 \%$, a weight ratio of dry matter to the total weight of said cheese of greater than or equal to $40 \%$, and a weight ratio of calcium to the weight of the TNM in said mozzarella cheese between $0.10 \%$ and $2.80 \%$.

S. The mozzarella cheese according to claim 12 , having a $\mathrm{pH}$ greater than or equal to 5.10 and less than or equal to 5.40 .

T. The method according to claim 1, wherein the second temperature is between $35^{\circ} \mathrm{C}$. and $55^{\circ} \mathrm{C}$.

U. The method according to claim 1 , wherein one or more acidification ferments and/or one or more aromatic enzymes modifying rheological properties and/or one or more flavour-producing ferments and/or one or more acidifying agents, are added during the adding step.

V. The method according to claim 1, comprising grinding the dough or pre-cheese mix, the grinding being carried out prior to the texturing.

W. The method according to claim 4, wherein the spinning/stretching occurs after the addition of steam or hot water to the dough or precheese mix obtained at the conclusion of the coagulation.

$X$. The method according to claim 5 , wherein the weight of the calcium and the weight of the total nitrogenous matter in the milk protein concentrates is between $1.70 \%$ and $2.70 \%$.

Y. The method according to claim 8 , wherein the dough or pre-cheese mix has a dry matter content of $40 \%$ to $65 \%$ by weight.
Z. The method according to claim 9, wherein the milk protein concentrates have a casein/TNM weight ratio greater than 0.70 .

\section{Process for foil ripening of cheese}

\section{US 2016100603 (USA)}

International patent classification A23C 19/068, A23C 19/14

Application: $20100682657,28.07 .2010$

Date of publication: 14.04 .2016

Priority: 20070020 018, 12.10.2007; 2008 EP 63 637, 10.10.2008

Proprietor: DSM IP ASSETS B.V. (NL)

\section{- The claims defining the invention are as follows}

i. A foil-ripened cheese that does not contain a plastic coating on the surface of the ripened cheese, characterized in that the foilripened cheese has a dry-rind, and the difference in $\mathrm{L}$ value at the surface of the cheese and at the center of the cheese block is higher than 0.5 , wherein $\mathrm{L}$ is a measure for the lightness of a color.

ii. The foil-ripened cheese of claim 1, wherein said difference in $\mathrm{L}$ value is higher than 1 .

iii. The foil-ripened cheese of claim 1, wherein said difference in $\mathrm{L}$ value is higher than 2 .

iv. The foil-ripened cheese of claim 1, wherein the foil-ripened cheese is a Gouda type.

v. The foil-ripened cheese of claim 1, wherein the foil-ripened cheese is a Emmental type.

vi. The foil-ripened cheese of claim 1, wherein the foil-ripened cheese is a Edam type.

Prepared foods having high efficacy omega 6/omega 3 balanced polyunsaturated fatty acids

\section{US 2016100616 (USA)}

International patent classification A21D 2/16, A23C 19/076, A23C 19/09, A23C 9/123, A23D 7/00, A23G 9/32, A23L 2/02, A23L 2/52

Application: 201414288 090, 27.05.2014

Date of publication: 14.04 .2016

Priority: 2012 US 33 973, 17.04.2012.

\section{(US) Proprietor: OMEGA FOODS LLC}

\section{The claims defining the invention are as follows}

a) A composition for manufacture of a food product, comprising a mixture of omega- 6 fatty acids, omega- 3 fatty acids, and an antioxidant, wherein the ratio of omega- 6 fatty acids to omega-3 fatty acids by weight is from about $0.01: 1$ to about $4: 1$; the omega 3 fatty acids comprise a short-chain polyunsaturated fatty acid ("PUFA") and a long-chain PUFA, where the ratio of shortchain PUFA to long-chain PUFA by weight is from about $0.01: 1$ to about $5: 1$; and a standard serving of the food product contains at least $50 \mathrm{mg}$ of long-chain PUFA.

b) The composition of claim 1, wherein the omega- 6 fatty acids, omega-3 fatty acids, and the antioxidant comprise an emulsion. 
c) The composition of claim 2, wherein the antioxidant is selected from the group consisting of a sinapyl compound, a sulfur containing antioxidant, ferulic acid containing antioxidant, vitamin $\mathrm{E}$, a tocotrienol, curcumin, inositol, and combinations thereof.

d) The composition of claim 3, wherein the antioxidant concentration of the emulsion is between about $5 \mathrm{ppm}$ to $115 \mathrm{ppm}$.

e) The composition of claim 3, wherein the antioxidant is vitamin $\mathrm{E}$ and inositol.

f) The composition of claim 1, wherein the long-chain PUFA is EPA, DHA, or a combination thereof.

g) The composition of claim 1, wherein the food product is a beverage.

h) The composition of claim 7 , wherein the beverage is selected from the group consisting of fruit smoothies, flavored beverages, orange juice, Italian ice, soy milk, and sports drinks.

i) The composition of claim 1, wherein the food product is a baked item.

j) The composition of claim 9, wherein the baked item is selected from the group consisting of puff pastry dough, sugar cookie, and white bread.

k) The composition of claim 1 , wherein the food product is a condiment or dressing.

1) The composition of claim 11, wherein the condiment or dressing is selected from the group consisting of mayonnaise, Caesar dressing, red French-style dressing, ranch-style dressing, blue cheese dressing, Italian dressing, Thousand island dressing, Lite Italian dressing, Three peppers dressing, Balsamic Vinaigrette Dressing, Raspberry Vinaigrette Dressing, horseradish sauce, ketchup sauce, and mustard sauce.

m) The composition of claim 1, wherein the food product is a grocery item.

n) The composition of claim 13, wherein the grocery item is selected from the group consisting of pasta sauce, alfredo sauce, pesto sauce, sundried tomato sauce, peanut butter, macaroni and cheese, corn snacks, potato chips, strawberry jam, and apple sauce.

o) The composition of claim 1, wherein the food item is a dessert.

p) The composition of claim 15 , wherein the dessert is selected from the group consisting of froze fruit desserts, ice cream, frozen yogurt, chocolate pudding, and vanilla pudding.

q) The composition of claim 1, wherein the food item is a deli item.

r) The composition of claim 17, wherein the deli item is selected from the group consisting of processed cheese sauce, margarine spread, cream cheese, hummus spread, refried bean dip, chicken nuggets, turkey breast lunch meat, and plain yogurt.

s) The composition of claim 1, wherein the food item is a breakfast item.

t) The composition of claim 19, wherein the breakfast item is selected from the group consisting of liquid egg product and liquid egg white product.

\section{Product preparation and cooking assembly US 2016106119 (USA)}

International patent classification A23C 19/09

Application: 201414516 607, 17.10.2014

Date of publication: 21.04 .2016

(US) Proprietor: GENERAL MILLS, INC.

\section{The claims defining the invention are as follows}

a) A method of preparing and cooking cheese crisps comprising: positioning an insert, including an array of funnel members, upon a mold, including an array of wells, such that each of the funnel members is freely received in a respective one of the wells; supplying cheese into the array of funnel members; removing the insert from upon the mold, causing the cheese within each funnel member to only partially fill a respective said well of the array of wells; heating the cheese in the mold; allowing the cheese to cool within the mold to form cheese crisps; and removing the cheese crisps from the mold.

b) The method of claim 1, wherein supplying cheese into the array of funnel members includes uniformly filling each of the funnel members with a calibrated amount of cheese.

c) The method of claim 2, wherein the cheese is supplied as shredded cheese.

d) The method of claim 2, wherein the cheese is supplied as cubes or granules of cheese.

e) The method of claim 2, wherein filling each of the funnel members includes placing a quantity of cheese on an upper surface of the insert, spreading the cheese into the funnel members and removing excess cheese from the upper surface.

f) The method of claim 2, wherein, upon removing the insert, each of the wells is no more than three-quarters full of the cheese.

g) The method of claim 6, wherein each of the wells receives between 2-3 grams of cheese.

h) The method of claim 1, wherein positioning the insert upon the mold includes resting lowermost edges of the funnel members on bottom walls of the wells.

i) The method of claim 1, further comprising: upon heating the cheese, developing grease upon the cheese within the wells, with the grease be retained below open top portions of the wells.

j) The method of claim 9 wherein, upon cooling the cheese, the grease soaks into the cheese crisps.

k) The method of claim 1 wherein, after cooling, the cheese crisps are recessed within the wells such that no webbing exists between the cheese crisps of adjacent ones of the wells.

1) The method of claim 1, wherein removing the cheese crisps from the mold includes flexing the mold.

m) The method of claim 1, wherein the step of supplying cheese includes supplying a melting cheese into the array of funnel members.

n) A product preparation and cooking assembly comprising: a mold including a base and an array of wells, with each well 
having a bottom wall, at least one side wall, and an open top; and an insert including a plate and an array of funnel members, with each funnel member having a lower opening, at least one side wall with a lowermost edge, and an upper opening, wherein the insert is configured such that, upon being placed on the mold, each of the funnel members is aligned with a respective one of the wells and sized to be freely received in the respective one of the wells.

o) The product preparation and cooking assembly of claim 14 , wherein the insert is configured such that, upon being placed on the mold, the lowermost edge of the at least one side wall of each funnel member rests on the bottom wall of the respective one of the wells.

p) The product preparation and cooking assembly of claim 15 , wherein the insert is further configured such that, upon completely filling each of the funnel members with a food product and removing the insert from upon the mold, the food product only partially fills each of the wells.

q) the product preparation and cooking assembly of claim 14, wherein the mold is made of a flexible material.

r) The product preparation and cooking assembly of claim 17 , wherein the flexible material is silicone.

s) The product preparation and cooking assembly of claim 14 , wherein the at least one side wall of each well and the at least one side wall of each funnel member constitutes an annular side wall, with a diameter of the at least one side wall of each funnel member being less than a diameter of the at least one side wall of each well.

t) The product preparation and cooking assembly of claim 14, the annular side wall of each well angles upwardly and outwardly from the bottom wall.

\section{Method for producing processed cheese JP 5909596 (Japan)}

International patent classification A23C 19/05, A23C 19/08, A23C $19 / 082$

Application: 20130073149, 29.03.2013

Date of publication: 26.04 .2016

Priority: 2014 JP 59 223, 28.03.2014

Proprietor: MORINAGA MILK INDUSTRY CO., LTD. (JP)

\footnotetext{
Abstract

A processed cheese is produced by producing a natural cheese $(\mathrm{N})$ via an acidification step, a coagulation step and a dehydration step described below, and then using the obtained natural cheese $(\mathrm{N})$ for at least $5 \%$ by mass of an ingredient cheese. The acidification step is a step of acidifying a milk to obtain an acidified milk having a $\mathrm{pH}$ of 5.8 to 6.4 , in which an acid component is added to the milk to achieve the required $\mathrm{pH}$ for the acidified milk, the coagulation step is a step of obtaining a curd by adding a milk coagulating enzyme to the acidified milk to cause coagulation, without adding a lactic acid bacterium starter, and the dehydration step is a step of obtaining the natural cheese $(\mathrm{N})$ by separating whey from the curd, and includes an enzyme inactivation step of inactivating the milk coagulating enzyme by cooking the curd to at least $55 \mathrm{C}$ at a rate of temperature increase of not more than $1 \mathrm{C}$ per minute.
}

\section{Cheese-containing food and method for producing same \\ JP 2016047059 (Japan)}

International patent classification A23C 19/09, A23L 23/00, A23L 23/10, A23L 35/00

Application: 20100004 761, 13.01.2010

Date of publication: 07.04.2016

Proprietor: MEIJI CO., LTD. (JP)

\section{Abstract}

Provided are a production method, whereby a cheese-containing food allowing consumers to easily enjoy the texture of natural cheese and so on can be produced, and the cheese-containing food produced by said method. The production method comprises crushing a cheese, mixing the same with a powdery soup stock and ingredients (food materials to be used as ingredients in soup), and pressurizing and reshaping the resulting mixture. A soup, which allows consumers to enjoy the texture and stringiness of natural cheese, can be prepared by putting the cheese-containing food obtained by the aforesaid production method in a cup, etc., pouring an appropriate amount of hot water and thus dissolving the food. Thus, an instant soup product, which allows consumers to easily enjoy the texture of natural cheese and so on, can be obtained and the scope of cheese intake at home can be broadened.

\section{Cheese and method for its manufacturing JP 201605232 I (Japan)}

International patent classification A23C 19/05, A23C 9/142

Application: 20150227 741, заявлено 20.11.2015

Date of publication: 14.04 .2016

Priority: 20090006 001, 30.09.2009

Proprietors: Martikainen Emmi (FI), Uusi-Rauva Janne (FI)

\section{Claim}

A method for improving organoleptic properties of a ripened cheese having a sodium content of at most $0.3 \%(\mathrm{w} / \mathrm{w})$ and/or a fat content of at most $30 \%(\mathrm{w} / \mathrm{w})$, comprising a step of adding milkand/or whey-based minerals and/or one or more biologically active peptides to a milk raw material.

\section{Cheese anticake for enhanced melt \\ JP 20165 I 2025 (Japan)}

International patent classification A23C 19/068

Application: 20160500 634, 05.03.2014

Date of publication: 25.04 .2016

Priority: 201313840 020, 15.03.2013; 2014 US 20 581, 05.03.2014.

Proprietors: SMITH GARY FRANCIS (US), CHARINTRANOND WIBUL (US), GASS PAUL V. (US), LEVINE BRIAN E. (US), MCPHERSON ANDREW E. (US)

\section{Claim}

i. A particulate natural cheese product comprising: 
ii. A natural cheese including a plurality of particulate natural cheese pieces each having an outer surface thereof;

iii. A modified starch applied to the particulate natural cheese pieces, the modified starch providing intact starch granules including amylopectin and substantially no amylose on the natural cheese pieces effective as an anticaking agent; and

iv. A uniform melt of the natural cheese and a uniform distribution of the amylopectin with substantially no intact starch granules and substantially no starch agglomerates of the amylopectin when the shredded natural cheese is melted.

\section{Cheese and method for its manufacturing}

\section{EP 3007563 (The European patent office)}

International patent classification A23C 19/064, A23C 19/09

Application: 20140739 502, 09.06.2014

Date of publication: 20.04.2016

Priority: 20130005 634, 10.06.2013; 2014 FI 50 466, 09.06.2014.

(FI) Proprietors: Valio, LTD.

\section{Claims}

a) A method of making cheese having a ratio of $\mathrm{K} / \mathrm{Na}$ of more than 0.2 to 4.0 wherein cheese is salted with a salting agent comprising milk minerals and $\mathrm{NaCI}$.

b) The method of claim 1 wherein the ratio of $\mathrm{K} / \mathrm{Na}$ is more than 0.8 , more specifically 0.8 to 1.2 or 0.52 to 3.2 .

c) he method of claim 1 or 2 wherein $\mathrm{K}$ content of cheese is more than $0.08 \%$, specifically more than $0.2 \%$, more specifically more than $0.3 \%$.

d) The method of any one of the preceding claims wherein milk minerals and $\mathrm{NaCI}$ are each provided as a separate salting agent.

e) The method of any one of the preceding claims wherein milk minerals are provided as a milk mineral concentrate obtained by a process wherein

i. Milk is subjected to ultrafiltration to provide an ultrafiltration permeate,

ii. The ultrafiltration permeate is subjected to nanofiltration to provide a nanofiltration permeate,

iii. The nanofiltration permeate is subjected to reverse osmosis to provide a reverse osmosis retentate as the milk mineral concentrate.

f) The method of claim 5 wherein the dry matter content of the milk mineral concentrate is about $9 \%$ to about $40 \%$, specifically about $16 \%$.

g) The method of any one of the preceding claims wherein the concentration of $\mathrm{NaCI}$ is in the range of about $16 \%$ to saturated, specifically about $18 \%$.

h) The method of any one of the preceding claims wherein cheese is salted with milk minerals and $\mathrm{NaCI}$ or a combination thereof in at least one salting step in any order.

i) The method of claim 8 wherein cheese is subjected to brine salting, surface salting or a combination thereof. j) The method of claim 8 or 9 wherein cheese is first salted with milk minerals followed by salting with NaCI.

k) The method of claim 8 or 9 wherein cheese is first salted with $\mathrm{NaCI}$ followed by salting with milk minerals.

1) The method of claim 8 or 9 wherein cheese is first salted with milk minerals, then with $\mathrm{NaCI}$ followed by further salting with milk minerals.

m) The method of any one of claims 9 to 12 wherein the brine salting with milk minerals is carried out for about 0.5 to about 96 hours.

n) The method of any one of the preceding claims, wherein a $\mathrm{NaCl}$ content of cheese is more than $0.81 \%$ to $5.0 \%$, specifically more than $0.81 \%$ to $1.3 \%$, more specifically $1.3 \%$.

o) The method of any one of the preceding claims, wherein the cheese is ripened cheese.

p) Ripened cheese having a ratio of $\mathrm{K} / \mathrm{Na}$ of 0.39 to 4.0 , specifically more than 0.8 , more specifically to 1.2 , and a $\mathrm{K}$ content of more than $0.08 \%$.

q) Ripened cheese of claim 16 wherein the $\mathrm{K}$ content of cheese is more than $0.2 \%$, specifically more than $0.3 \%$.

r) Ripened cheese of claim 16 or 17 wherein a NaCI content of cheese is more than $0.81 \%$ to $5.0 \%$, specifically more than 0.81 $\%$ to $1.3 \%$, more specifically $1.3 \%$.

s) Cheese having a ratio of $\mathrm{K} / \mathrm{Na}$ of more than 0.2 to 4.0 , which is salted with a salting agent comprising milk minerals and NaCI.

Spreadable high protein cream cheese products and methods of making the same

\section{EP 3010349 (The European patent office)}

International patent classification A23C 19/076, A23C 19/09

Application: 20140737 480, 20.06.2014

Date of publication: 27.04 .2016

Priority: 201361 837 990P, 21.06.2013; 2014 US 43 399, 20.06.2014.

Proprietor: Kraft Foods Group Brands LLC. (US);

\section{Claims}

i. A high protein cream cheese composition having organoleptic characteristics of cream cheese with lower amounts of protein, the high, protein cream cheese composition comprising; about 8 to about 20 percent total protein provided from a cheese curd, a cultured dairy liquid, and one or more high protein powders having about 70 percent or greater protein relative to the protein powder;an amount of total fat, but not more than about 12 percent total fat; and a powder-to-moisture ratio from about 0.08 to about 0.25 and a protein-to-fat ratio from about 0.7 to about 3,5 so that the high protein cream cheese composition exhibits the spreadability of cream cheese with lower amounts of protein.

ii. The high protein cream cheese composition of claim 1 , further comprising about 6 to about 14 percent total fat and about 59 to about 72 percent moisture.

iii. The high protein cream cheese composition of any preceding 
claim, wherein the cheese curd includes about 6 to about 10 percent protein, about 20 to about 25 percent fat, and a $\mathrm{pH}$ of about 4.3 to about 4.6 .

iv. The high protein cream cheese composition of any preceding claim,, wherein the cheese curd has a ratio of casein to whey of about $85: 15$ or greater levels of casein.

v. The high protein cream cheese composition of any preceding claim, wherein the cheese curd is eufchatel curd.

vi. The high protein cream cheese composition of any preceding claim, wherein the cultured dairy liquid includes a fermented skim milk retentate produced by ultrafiltration.

vii. The high protein cream cheese compositio of any preceding claim, wherein the fermented skim milk retentate has about 75 to about 80 percent moisture, about 14 to about 20 percent protein, and fat, but no more than about 1.5 percent fat.

viii. The high protein cream cheese composition of an preceding claim, wherein the fermented skim milk retentate has a $\mathrm{pH}$ of about 4.7 to about 5.2 .

ix. The high protein cream, cheese composition of any preceding claim, wherein the one or more high protein powders are selected from the group consisting of milk protein concentrate, milk protein isolate, whey protein concentrates, whey protein isolates, and mixtures thereof,

$\mathrm{x}$. The high protein cream cheese composition of any preceding claim, wherein the one or more high protein powders have a. ratio of casein to whey of about 80:20 or higher amounts of casein,

xi. The high protein cream cheese composition of any preceding claim, further including about 280 to about $385 \mathrm{mg} / 100$ grams of calcium provided from, one of the cheese curd, the cultured dairy liquid, the one or more high protein powders, and mixtures thereof.

xii. The high protein cream cheese composition of any preceding claim, wherein the high protein cream cheese composition is free of added emulsifying salts,

xiii. The high protein cream cheese composition of any preceding claim, wherein the high protein cream cheese composition has a ratio of casein to whey of about 80:20 or higher casein,

xiv. A method of making a high protein cream cheese composition having organoleptic characteristics of cream cheese with lower amounts of protein, the method comprising: providing a cheese curd having about 6 to about 10percent protein, about 20 to about 25 percent fat, and a $\mathrm{pH}$ of about 4.3 to about 4.6 ; adding a cultured dairy liquid having a higher $\mathrm{pH}$ to the cheese curd to raise the $\mathrm{pH}$ and form a dairy mixture; blending one or more high protein dairy powders having about 70 percent protein or more, relative to the dairy powder, into the dair mixture to form a cream cheese mixture; and homogenizing the cream cheese mixture to form the high protein cream cheese composition having about 8 to about 20 percent protein and the spreadability of cream cheese with lower amounts of protein.

xv. The method of claim 14, wherein the cream cheese composition has about 8 to about 14 percent total fat and about 59 to about 72 percent moisture. xvi. The method of any of claims 14 to 15 , wherein the cheese curd has a ratio of casein to whey of about 85:15 or greater levels of casein,

xvii. The method of any of claims 14 to 16 , wherein the cheese curd is Neufchatel curd.

xviii. The method of any of claims 14 to 17 , wherein the cultured dairy liquid is a fermented skim milk retentate produced by ultrafiltration.

xix. The method of any of claims 14 to 18 , wherein the fermented skim, milk retentate has about 75 to about 80 percent moisture, about 14 to about 20 percent protein, and fat, but no more than about 1.5 percent fat.

xx. The method of claim 19, wherein the fermented skim milk retentate has a $\mathrm{pH}$ of about 4.7 to about 5.2.

xxi. The method of any of claims 14 to 20 , wherein the one or more high protein powders are selected from the group consisting of milk protein concentrate, milk protein isolate,, whey protein concentrates, whey protei isolates, and mixtures thereof.

xxii. The method of any of claims 14 to 21 , wherein the one or more high protein powders have a ratio of casein to whey of about $80: 20$ or higher amounts of casern.

xxiii. The method of any of claims 14 to 22 , further including about 280 to about $385 \mathrm{mg} / 100$ grams of calcium provided from one of the cheese curd, the cultured dairy liquid, the one or more high protein powders, and mixtures thereof.

xxiv. The method of an of claims 14 to 23 , wherein the high protein cream cheese composition is free of added emulsifying salts,

xxv. The method of any of claims 14 to 24 , wherein the high protein cream cheese composition has a ratio of casein to whey of about 80:20 or higher casein.

\section{Cheese composition and process for making it}

\section{WO 2016050844 (The patent cooperation Treaty)}

International patent classification A23C 19/05, A23C 19/055, A23C 19/082, A23C 19/09, A23C 19/093

Application: 2015 EP 72 555, 30.09.2015

Date of publication: 07.04.2016

Priority: 20140187 675, 03.10.2014.

Proprietor: NESTEC S.A. $(\mathrm{CH})$

\section{Claims}

a) A process for making a cheese composition comprising the steps of:

b) Blending $25-75 \mathrm{wt} \%$ cheese with $25-75 \mathrm{wt} \%$ liquid milk to obtain a cheese-milk blend;

c) Pasteurizing the cheese-milk blend at a temperature of $72^{\circ} \mathrm{C}$ or above;

d) Optionally homogenizing the pasteurized cheese-milk blend;

e) Acidifying the pasteurized cheese-milk blend to a $\mathrm{pH}$ from 4.0 to 6.5 ; 
f) Cooling the acidified cheese-milk blend to a temperature of $8^{\circ} \mathrm{C}$ or below.

g) The process according to claim 1, wherein step a) is blending $40-65 \mathrm{wt} \%$ cheese with $35-60 \mathrm{wt} \%$ liquid milk to obtain the cheese-milk blend.

h) The process according to claim 1 or 2 , wherein step a) further comprises adding milk protein concentrate, milk fat concentrate and/or a vegetable fat to the cheese-milk blend.

i) The process according to one of the claims 1-3, wherein the pasteurized cheese-milk blend in step $\mathrm{d}$ ) is acidified to a $\mathrm{pH}$ from 4.0 to 5.8 , preferable to a $\mathrm{pH}$ from 4.3 to 5.5 , more preferably to a $\mathrm{pH}$ from 4.5 to 5.2 .

j) The process according to one of the claims 1-4, wherein the pasteurized cheese-milk blend in step d) is acidified by lactic fermentation.

k) The process according to claim 5, wherein lactic fermentation is initiated by an addition of mesophilic and/or thermophilic lactic acid bacteria.

1) The process according to claim 6 , wherein the lactic fermentation is carried out at a temperature from $25^{\circ} \mathrm{C}$ to $45^{\circ} \mathrm{C}$ for at least 2hours, preferably for at least 4hours .

$\mathrm{m})$ The process according to one of the claims 1-7, wherein rennet is added to the pasteurized cheese-milk blend in step d) .

n) The process according to one of the claims 1-8, wherein the cheese is selected from the group consisting of goat cheese, blue cheese, fresh cheese, Camembert cheese, Brie cheese, cottage cheese, cream cheese, feta cheese, ricotta cheese, Comte, Gouda, Gruyere, Emmental and mozzarella cheese, or a combination thereof.

o) The process according to claim 9, wherein the cheese is a combination of at least two cheeses selected from the group.

p) The process according to one of the claims 1-10, which does not comprise a step of adding an emulsifier, a stabilizer and/or a thickener.

q) The process according to one of the claims 1-11,comprising a step of adding herbs and/or spices.

r) A cheese composition obtainable by the process according to one of the claims $1-12$

s) A food product comprising the cheese composition according to claim 13

t) The food product according to claim 14 which is a pizza product, a sandwich product or a prepared dish, preferably a prepared pasta dish.

Physically stable liquefied cheese composition and process for making it

\section{WO 2016050420 (The patent cooperation Treaty)}

International patent classification A23C 19/00, A23C 19/068, A23C $19 / 076$

Application: 2015 EP 69 388, 25.08.2015

Date of publication: 07.04.2016
Priority: 201462059 292P, 03.10.2014

Proprietor: NESTEC S.A. (CH)

\section{Claims}

a) A physically stable cheese composition comprising: 55$75 \mathrm{wt} \%$ soft cheese, and $25-45 \mathrm{wt} \%$ water; where in the cheese composition has a viscosity from 2 ' 000 to 4 ' $500 \mathrm{cP}$ at $10^{\circ} \mathrm{C}$, and a $\mathrm{pH}$ from 4.0 to 4.8 ; and wherein particles comprised in the cheese composition have a median particle size distribution of 0.6 to 10 micrometer, preferably of 0.9 to 7 micro-meter.

b) The cheese composition according to claim 1, having a viscosity from 200 to $4^{\prime} 300 \mathrm{cP}$ at $10^{\circ} \mathrm{C}$

c) The cheese composition according to claim 1 or 2 , having a $\mathrm{pH}$ from 4.4 to 4.6 .

d) The cheese composition according to one of the claims 1- 3, wherein the soft cheese is selected from the group consisting of goat cheese, Gorgonzola cheese, blue cheese, fresh cheese, Camembert cheese, Brie cheese, cottage cheese, cream cheese, feta cheese, ricotta cheese and mozzarella cheese, or a combination thereof.

e) The cheese composition according to claim 4, wherein the soft cheese is a combination of at least two cheeses selected from the group.

f) The cheese composition according to one of the claims 1-5, wherein the total solids composition of the cheese composition is from $25-42 \%$, preferably from $27-32 \%$.

g) The cheese composition according to one of the claims 1- further comprising herbs and/or spices.

h) The cheese composition according to one of the claims 1- not comprising an added emulsifier, stabilizer and/or binder.

i) Process for making a physically stable cheese composition comprising the steps of:

j) Mixing 55-75 wt $\%$ soft cheese with $25-45 \mathrm{wt} \%$ water at room temperature with a blender;

k) Adjusting the $\mathrm{pH}$ of the soft cheese-water mixture to a $\mathrm{pH}$ from 4.0 - 4.8 ;

1) Heating the soft cheese-water mixture under continuous mixing to a temperature of $50-65^{\circ} \mathrm{C}$;

m) Homogenizing the heated soft cheese-water mixture under pressure at $30-500$ bar at a temperature of $50-65^{\circ} \mathrm{C}$; e) cooling the heat treated soft cheese-water mixture to a temperature of $4-20^{\circ} \mathrm{C}$.

n) The process according to claim 9, where the heating of the soft cheese-water mixture in step c) and d) is to a temperature of $50-60^{\circ} \mathrm{C}$.

o) The process according to claim 9 or 10 , which does not comprise a step of adding an emulsifier, a stabilizer and/or a binder.

p) The process according to one of the claims 9-11, comprising a step of adding herbs and/or spices.

q) The process according to one of the claims 9-12, wherein the process does not comprise a step of heating the cheese composition to a temperature above $65^{\circ} \mathrm{C}$, preferably above $75^{\circ} \mathrm{C}$ 
r) Food product made with use of the cheese composition according to one of the claims $1-8$.

s) The food product of claim 13 which is a pizza, a hot- pocket sandwich or a prepared dish

\section{Acknowledgements}

None.

\section{Conflict of interest}

Author declares that there is no conflict of interest. 